\title{
Translation of nutrient recommendations into personalized optimal diets for Chinese urban lactating women by linear programming models
}

Kai Yu1, Yong Xue ${ }^{1,2}$, Wenzhi Zhao ${ }^{1}$, Ai Zhao $^{3}$, Wenjun Li $i^{4}$, Yumei Zhang ${ }^{1 *}$ and Peiyu Wang ${ }^{3}$

\begin{abstract}
Background: Lactating women need to consume a high-quality diet to replete nutrient stores depleted during pregnancy and to ensure sufficient nutrition for breastfeeding. However, several studies reported suboptimal dietary quality and nutrient intake of lactating mothers in China. The objectives of this study was to apply dietary modeling method to develop individualized optimal diets, which meet the nutrient requirements for lactating women in urban China.

Methods: Data were collected from a sample of 576 lactating women from 0 to 240 days postpartum during the Maternal Infant Nutrition Growth study conducted between 2011 and 2012 in three cities including Beijing, Guangzhou, and Suzhou. Dietary intake data were collected with an interviewer-administered 24-h survey. Linear programming was applied to develop dietary plans that meet recommendations for lactation women in the China Dietary Reference Intakes 2013 and the Chinese Dietary Guideline 2016, while with least deviation from the observed dietary intake.

Results: Through dietary modeling, individual optimal diets were developed for 576 lactating women. The optimal diets met all the food and nutrient intake constraints set in the linear programming models. The large difference between observed and optimized diets suggests that the nutrient needs of lactating mothers in China may only be met after substantial dietary changes. In addition, the analysis showed that it was difficult to meet the recommended intake for six nutrients: vitamin A, vitamin B1, vitamin B6, calcium, selenium, and dietary fiber. Moreover, four clusters in the optimized diets were identified by K-means cluster analysis. The four clusters confirmed that the optimal diets developed by linear programming could characterize the variety in dietary habits by geographical regions and duration of lactation.
\end{abstract}

Conclusion: Linear programming could help translate nutrient recommendations into personal diet advices for a sample of urban lactating mothers from China. The study showed that dietary modeling is helpful to support healthy eating of lactation women by translating dietary guidelines into personalized meal plans.

Trial registration: The Maternal Infant Nutrition Growth study was registered in ClinicalTrials.gov with identifier NCT01971671. Registration date October 29, 2013.

Keywords: Lactation mother, Linear programming, Nutrient recommendation, Personalized optimal diets

\footnotetext{
* Correspondence: zhangyumei@bjmu.edu.cn

'Department of Nutrition and Food Hygiene, School of Public Health, Peking

University, Beijing, China

Full list of author information is available at the end of the article
}

(c) The Author(s). 2018 Open Access This article is distributed under the terms of the Creative Commons Attribution 4.0 International License (http://creativecommons.org/licenses/by/4.0/), which permits unrestricted use, distribution, and reproduction in any medium, provided you give appropriate credit to the original author(s) and the source, provide a link to the Creative Commons license, and indicate if changes were made. The Creative Commons Public Domain Dedication waiver (http://creativecommons.org/publicdomain/zero/1.0/) applies to the data made available in this article, unless otherwise stated. 


\section{Background}

According to the recommendation on maternal nutrition from the International Federation of Gynecology and Obstetrics (FIGO), healthy eating during lactation period is essential to help mothers to rebuild body stores of nutrients depleted during pregnancy, as well as to conserve nutrient stores for ensuring supply of breast milk without compromising maternal nutrition reserve [1]. Considering the increasing nutritional need to support infant's growth, the nutritive demands of lactation mothers are greater than non-lactating women [2]. However, previous studies from different countries reported suboptimal dietary quality and nutrient intake of lactation mothers [3-5].

The dietary pattern of a lactating mother is influenced by her cultural and social context. Reports from countries like Spain [6], UK [7], US [8], and Brazil [9] showed little or no change in dietary pattern from preconception to postpartum period. However, due to the influence of cultural beliefs such as postpartum "confinement period", diet changes during pregnancy and postpartum periods were found in some ethnic groups [10]. In China, the confinement period is called zuo yuezi (literal meaning as "doing the month" or "sitting the month"), which includes a set of practices to guide diet, activity and hygiene based on traditional beliefs and theories [11]. Our previous study found that urban Chinese women within 5-30 day postpartum had a significant lower nutrient intake compared to those after 30 day postpartum [12]. The problem of inadequate nutrient intakes was also reported from a sample of lactating women within 90 day postpartum from Fujian Province in China [13]. Considering the multiple factors affecting dietary habits of lactating women, it is important to take into account cultural and individual preferences when providing dietary advices.

Dietary modeling is an approach to derive optimal diets by meeting an objective function subject to a set of constraints such as nutrient intake recommendation [14]. Based on linear programming, dietary modeling can help solve the complex problem of designing diets that meet nutrient recommendations while maintaining the local food habits and the intake of culture-specific foods [15]. The dietary modeling problem was first proposed by the Nobel Prize laureate George Stigler in 1945, when he tried to solve the cost minimization problem of designing a balanced diet plan that meets major nutrient recommendation [16]. Later, George Dantzig developed the theory of linear programming which formally solved this diet problem. With the availability of readily accessible computer technology, linear programming have been used for different purposes in nutrition and public health: translating nutrient recommendations into individual food choices $[15,17]$; characterization of sustainable diets meeting a list of nutritional, economics and environmental constraints [18-20]; development of diet-based intervention for developing countries solely based on local food available [21, 22]; assessment of compatibility between food- and nutrient-based recommendations [23]. Linear programming was also applied to generate nutrition advice for individuals participating in a large scale, randomized controlled trial to compare effect on dietary behavior change between personalized nutrition advices versus conventional population-based recommendation [24].

Considering the importance of nutrition for lactating mothers and the suboptimal nutrient intake for this group in China, individualized dietary advice maybe helpful to provide realistic dietary guidance. However, to the best of our knowledge, no previous study have reported for developing individualized optimal diets based on linear programming in Chinese population. Therefore, the objective of the present study is to develop individual optimal dietary plan for a sample of urban Chinese lactating mothers. Based on linear programming, the aim of the optimal diets are to achieve nutrient recommendation in Dietary Reference Intakes (DRIs), while accounting for individual food intakes. In addition, by characterizing the "optimal diets" derived from dietary modelling, we also want to specify the modification needed for meeting DRIs with minimal deviation from current diets.

\section{Methods \\ Subjects}

The dietary data of lactating mothers were obtained from the Maternal Infant Nutrition and Growth Study (MING Study), which is a cross-sectional survey on dietary and nutrition status of pregnant women, lactating women, infants and toddlers aged $0-3$ years. In the MING study, lactating women were selected from three cities (Beijing, Suzhou, and Guangzhou) with a purposive sampling approach. The three cities were chosen for representing north (Beijing), middle (Suzhou) and south (Guangzhou) of China. In each city, one hospital and one community-based maternal and child health care center were randomly selected from a computer-generated hospital list. At each site, mothers at lactation period 0-240 days were randomly chosen according to registration information provided by hospital. For lactating mother in the period of 0-4 day postpartum, recruitment was conducted at the hospital. For subjects at lactating stage of 5-240 days, requests of interview were conducted by phone. The inclusion criteria are: healthy women aged between 18 and 45 years, with healthy full term delivery, without cardiovascular and metabolic diseases, without using any hormone in past three months and without postpartum depression.

The final sample size of lactating women in MING study was 580 . By excluding four subjects with daily energy intake lower than $200 \mathrm{kcal}$ in the observed diets, 576 lactating mothers were included in the present 
study, including 214 from Beijing, 180 from Guangzhou, and 182 from Suzhou. The numbers of subjects from different lactation stages are 106 from 0 to 4 day postpartum, 187 from 5 to 30 day postpartum, and 283 from 31 to 240 day postpartum.

\section{Dietary data collection and preparation}

Dietary intake status of lactating mothers was assessed by one cycle $24 \mathrm{~h}$ recall. During the interview, trained interviewers asked participants to report all food and beverages including seasonings and supplements consumed the day before interview. Quantity of item consumed and time or description of the meal were recorded. Measurement aids including standard bowls, plates and spoons, as well as a picture booklet of common foods consumed in China were used to help quantification of food items. All food, beverages and supplements were recorded. The energy and nutrient intake of lactating mothers were calculated based on the Chinese Food Composition Table [25].

In the present study, all food items recorded were categorized into 41 food groups according to the food group codes in the Chinese Food Composition Table. The resulted intakes in food groups are defined as "observed diets". The nutrient profiles of the 41 food groups were established according to the method in previous studies $[15,26]$. To develop nutrient profiles for the 41 food groups, relative consumption of each food item under corresponding food groups was estimated based on the $24 \mathrm{~h}$ recall data. We assigned a weight to the nutrients from each food item that corresponded to the percentage consumption in its food group. The nutrient profile for each food group was then established.

\section{Description of optimized model}

To identify optimal diets that satisfy nutrition recommendation with least departure from current diet, linear programing approach is applied in this study.

Linear programming is a mathematical approach employed to identify the optimal solution of an objective function, which is dependent on a set of decision variables restricted by various linear constraints [27, 28]. In the current study, the objective function was to minimize differences in food intake between the observed and the optimized food group intakes by lactating mothers.

According to previous studies [15, 27], the objective function was mathematically described as the sum of the absolute values of differences between the intake of each food group in the optimized diets and that in the observed diets divided by that in the observed diets, as to standardize the difference across food groups:

$$
Y=\sum_{i=1}^{i=41}\left|\frac{x_{i}^{o p t}-x_{i}^{o b s}}{x_{i}^{o b s}}\right|
$$

where $Y$ is the objective function to minimize, $x_{i}^{o p t}$ denotes the quantity $(\mathrm{g})$ of food group $i$ in the optimized diets, and $x_{i}^{o b s}$ is the quantity $(\mathrm{g})$ of food group $i$ intake in the surveyed food data.

Because of its nature as an absolute value, $Y$ was nonlinear. To meet the requirement of linear programming, $Y$ was transformed into a linear function using the goal programming approach [21]. New decision variables $\geq 0$ and representing the positive $\left(P_{1}\right.$ to $\left.P_{41}\right)$ and negative $\left(N_{1}\right.$ to $\left.N_{41}\right)$ deviation from the observed food group quantity were created and defined as follows:

$$
\text { If } x_{i}^{o p t}<x_{i}^{o b s}, \text { then } N i=\frac{x_{i}^{o b s}-x_{i}^{o p t}}{x_{i}^{o b s}} \text { and } P_{i}=0
$$

Table 1 Nutrient constraints included in the linear

\begin{tabular}{|c|c|c|}
\hline $\begin{array}{l}\text { Dietary Reference } \\
\text { Intake Constraints }\end{array}$ & $\begin{array}{l}\text { Lower limits based on } \\
\text { RNI, Al or AMDR }\end{array}$ & $\begin{array}{l}\text { Upper limits based on } \\
\text { AMDR, PI-NCD or UL }\end{array}$ \\
\hline Energy (kcal/d) & 2300 (EER) & \\
\hline \multicolumn{3}{|l|}{ Macronutrients (AMDR) } \\
\hline $\begin{array}{l}\text { Energy supply from } \\
\text { carbohydrate (\%) }\end{array}$ & $\geq 50$ & $\leq 65$ \\
\hline $\begin{array}{l}\text { Energy supply from } \\
\text { fat }(\%)\end{array}$ & $\geq 20$ & $\leq 30$ \\
\hline \multicolumn{3}{|l|}{ Nutrients with RNI or Al } \\
\hline Protein (g/d) & $\geq 80$ & \\
\hline Vitamin $B_{1}(m g / d)$ & $\geq 1.5$ & \\
\hline Vitamin $B_{2}(m g / d)$ & $\geq 1.5$ & \\
\hline Vitamin C(mg/d) & $\geq 150$ & $\leq 2000$ \\
\hline Vitamin $E(\mu \mathrm{g} / \mathrm{d})$ & $\geq 17(\mathrm{Al})$ & $\leq 700$ \\
\hline 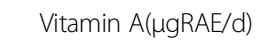 & $\geq 1300$ & $\leq 3000$ \\
\hline Vitamin $B_{6}(m g / d)$ & $\geq 1.7$ & $\leq 60$ \\
\hline Niacin (mg/d) & $\geq 15$ & $\leq 35$ \\
\hline Calcium (mg/d) & $\geq 1000$ & $\leq 2000$ \\
\hline Phosphorus (md/d) & $\geq 720$ & $\leq 3500$ \\
\hline Potassium (mg/d) & $\geq 2400$ (Al) & \\
\hline Magnesium (mg/d) & $\geq 330$ & \\
\hline Iron (mg/d) & $\geq 24$ & $\leq 42$ \\
\hline Zinc (mg/d) & $\geq 12$ & $\leq 40$ \\
\hline Selenium $(\mu \mathrm{g} / \mathrm{d})$ & $\geq 78$ & $\leq 400$ \\
\hline Copper (mg/d) & $\geq 1.4$ & $\leq 8$ \\
\hline Manganese (mg/d) & $\geq 4.8(\mathrm{Al})$ & $\leq 11$ \\
\hline Sodium (mg/d) & $\geq 1500$ & $\leq 2000(\mathrm{Pl}-\mathrm{NCD})$ \\
\hline Dietary fiber (g/d) & $\geq 25(\mathrm{Al})$ & \\
\hline
\end{tabular}
programming optimization model

${ }^{\mathrm{a} V a l u e s}$ are RNI except for energy (EER), carbohydrate (AMDR), fat (AMDR), manganese (Al), potassium (Al), vitamin E (Al), and dietary fiber (Al). ${ }^{b}$ Values are UL except for energy (EER), carbohydrate (AMDR), fat (AMDR), and sodium (PI-NCD) 


$$
\begin{aligned}
& \text { If } x_{i}^{o p t}>x_{i}^{o b s} \text {, then } N i=0 \text { and } P i=\frac{x_{i}^{o b s}-x_{i}^{o p t}}{x_{i}^{o b s}} \\
& \text { If } x_{i}^{o p t}=x_{i}^{o b s} \text {, then } N i=0 \text { and } P_{i}=0 \\
& \text { Subject to : Pi-Ni }=\frac{x_{i}^{o p t}-x_{i}^{o b s}}{x_{i}^{o b s}}
\end{aligned}
$$

The new linear function call $Y^{\prime}$ was expressed as the sum of deviational variables and was minimized:

$$
Y^{\prime}=\sum_{i=1}^{i=41} P_{i}-N_{i}
$$

Each food group in the objective function was linked to the nutrient profile of this food group established for the present study as mentioned above. The linkage of food group intake to nutrient profile database allowed the model to calculate and check at all times whether nutritional constraints were satisfied.

For every lactating mother included in this study, a model was developed to identify a new individually modeled diet that fulfills all the nutritional constraints.

\section{Nutritional constraints for linear programming models}

Nutritional constraints were defined to allow linear programming models to seek optimal solutions. The sets of nutritional constraints include total dietary energy, nutritional targets, and maximal quantities of food groups.

The total dietary energy constraint was set equal to $2300 \mathrm{kcal} / \mathrm{d}$, as recommended as the Estimated Energy Requirement (EER) for lactating mother in Chinese Dietary Reference Intakes (DRIs) 2013 [29]. The adoption of an isocaloric approach was due to lack of physical activity level data in the survey; thus, the recommendation of energy intake taking into account of physical activity level could not be considered.

Nutrient constraints were set for 21 nutrients with recommended intake values from Chinese DRIs 2013. The lower limits of specific nutrients followed the corresponding value of Recommended Nutrient Intake (RNI) and Adequate Intake (AI). The upper limits were in accordance with Tolerable Upper Intake Level (UL) or Proposed Intakes for Preventing Non-Communicable Chronic Diseases (PI-NCD). For carbohydrate and fat, the ranges defined as Acceptable Macronutrient Distribution Ranges (AMDR) were applied as lower and upper bounds. Table 1 shows the details of nutrient constraints for each of the 21 nutrients.

The food group intake recommendations from Dietary Guideline for Chinese 2016 [30] were taken as reference to set up constraints for maximal quantities of each food group (Table 2). Food groups without recommendation were mainly processed foods. By considering typical serving size, the upper limits of solid food and sugar-sweetened beverages were defined as $100 \mathrm{~g}$ and $250 \mathrm{~g}$, respectively.

\section{Statistical analysis}

Linear programming models were developed for each individual of the 576 lactation women in this study. The output data of optimized diets include total diet weights and changes from observed diets.

For each of the 41 food groups, the quantity in their optimized diets vs. the corresponding observed diets, the percentage of increase or decrease for lactating women who consumed given food group, as well as changes of nutrient intakes between observed

\begin{tabular}{|c|c|c|c|c|c|}
\hline Food group & Upper limit (g) & Food group & Upper limit (g) & Food group & Upper limit (g) \\
\hline Wheat bun & 400 & Red \& yellow vegetable & 500 & Egg & 50 \\
\hline Wheat noodle & 400 & Other vegetable & 500 & Liquid milk & 500 \\
\hline Bread & 400 & Pickle & 500 & Yogurt & 500 \\
\hline Rice & 400 & Apple and pear & 350 & Milk powder & 500 \\
\hline Wheat flour product (fried) & 200 & Banana & 350 & Soup & 250 \\
\hline Wheat flour product (non-fried) & 400 & Processed fruit & 350 & Sugar-sweetened beverage & 250 \\
\hline Potato & 100 & Other fruit & 350 & Fast food & 100 \\
\hline Tuber & 100 & Citrus fruit & 350 & Fried snack & 100 \\
\hline Coarse grain & 150 & Pork & 75 & Non-fried snack & 100 \\
\hline Various beans & 150 & Poultry & 75 & Cake and ice-cream & 100 \\
\hline Soybean & 35 & Aquatic product ${ }^{\mathrm{a}}$ & 75 & Plant oil & 30 \\
\hline Nut & 35 & Other livestock meat & 75 & Animal oil & 30 \\
\hline Millet & 400 & Organ meat & 20 & Condiment & 6 \\
\hline Leafy vegetable & 500 & Processed meat & 50 & & \\
\hline
\end{tabular}
and optimized diets were calculated. The contribution of food groups to nutrients was also estimated from

Table 2 Food group intake constraints included in the linear programming model

${ }^{\mathrm{a}}$ Aquatic products refer to fish, shrimps, crabs, shellfish and other fishery products 
the optimized diets. For estimating sources of nutrients from food groups in the optimal diets, the weighted percentage contribution of each food group was calculated by adding the amount of a given nutrient provided by each food group for all participants and dividing by the total intake of that nutrient consumed by all participants from all foods and beverages in the optimal diets.

To evaluate whether the optimized diets derived from linear programming could reflect distinctive dietary habits by geographical locations and duration of lactation, K-means cluster analysis was employed to determine dietary clusters following the approach of Thorpe et al. [31]. The K-means cluster analysis needs to specify the number of clusters prior to analysis. A cluster contained $<10 \%$ number of participants in the total sample was considered not having adequate statistical power. The final clusters with each accounting for at least $10 \%$ subjects were examined for interpretability to confirm.

For characteristics of participants, mean value with standard errors were used for continuous variables, and counts and percentages for categorical values. Descriptive and difference analyses were performed with SPSS version 20.0 (SPSS Inc., USA). All of the reported $p$ values were 2-tailed, and those $<0.05$ were considered to be statistically significant. Solver add-in from Excel 2013 (Microsoft Inc., USA) was used for linear programming according to the method described by Briend et al. [16].

\section{Results}

Total and changes of diet weights between observed and optimized diets.

Optimized diets satisfying all nutritional constraints were obtained for every lactating mother. The total diet weights of optimized diets and the deviation from observed diets were shown in Table 3 . The mean variance between observed and optimized diets was $1325 \mathrm{~g}$, which suggests that the reach of optimal diets required substantial changes in food group intakes.

Significant differences in variation between the observed and the optimized diets were found among different cities. Compared to subjects from Beijing and Suzhou, lactating women from Guangzhou exhibited the significantly higher food intake changes required to achieve optimized diets.

The total diet weights were significantly different among different lactation stages. The mean value of total diet weights were highest for subjects from 31 to 240 day postpartum, with significant differences compared with those from 0 to 4 days and 5-30 days.

\section{Analysis of changes between observed and optimized diets}

Noticeable dietary changes were found between the observed and the optimized diets. Table 4 shows the comparison of food group consumption rates. The food group of organ meat is the only one with $100 \%$ consumption rate in the optimized diets, and organ meat was added in their

Table 3 Distribution of total diet weights of the optimized diets and variation from the observed diets

\begin{tabular}{|c|c|c|c|c|c|c|}
\hline & Mean & $P 5^{\mathrm{a}}$ & P25 & Median & P75 & P95 \\
\hline Total diet weight of optimized diets (g) & $1638 \pm 8.51$ & 1346 & 1487 & 1620 & 1752 & 2014 \\
\hline \multicolumn{7}{|l|}{ Different Cities (g) } \\
\hline Beijing & $1641 \pm 15.55^{\mathrm{ab}}$ & 1290 & 1462 & 1622 & 1785 & 2035 \\
\hline Guangzhou & $1680 \pm 13.27^{\mathrm{a}}$ & 1409 & 1568 & 1664 & 1767 & 2000 \\
\hline Suzhou & $1592 \pm 14.16^{b}$ & 1351 & 1435 & 1549 & 1724 & 1922 \\
\hline \multicolumn{7}{|l|}{ Different lactation stages } \\
\hline $0-4 d$ & $1521 \pm 16.29^{c}$ & 1271 & 1390 & 1543 & 1646 & 1797 \\
\hline $5-30 d$ & $1629 \pm 13.57^{b}$ & 1344 & 1488 & 1625 & 1745 & 1986 \\
\hline $31-240 d$ & $1687 \pm 12.49^{a}$ & 1388 & 1523 & 1667 & 1840 & 2084 \\
\hline $\begin{array}{l}\text { Variation between the observed } \\
\text { and the optimized diets (g) }\end{array}$ & $1325 \pm 17.94$ & 784 & 1034 & 1231 & 1539 & 2148 \\
\hline \multicolumn{7}{|l|}{ Different cities } \\
\hline Beijing & $1304 \pm 29.89^{b}$ & 723 & 1026 & 1209 & 1537 & 2153 \\
\hline Guangzhou & $1473 \pm 36.18^{a}$ & 811 & 1138 & 1354 & 1721 & 2424 \\
\hline Suzhou & $1206 \pm 22.82^{c}$ & 828 & 977 & 1155 & 1335 & 1873 \\
\hline \multicolumn{7}{|l|}{ Different lactation stages } \\
\hline $0-4 d$ & $1345 \pm 32.58$ & 952 & 1122 & 1246 & 1462 & 2032 \\
\hline $5-30 d$ & $1368 \pm 31.82$ & 867 & 1069 & 1290 & 1568 & 2347 \\
\hline $31-240 d$ & $1288 \pm 27.18$ & 748 & 972 & 1184 & 1513 & 2153 \\
\hline
\end{tabular}

${ }^{\mathrm{a}} \mathrm{P}$ stands for distribution [5th percentile (p5), first quartile (P25), median, third quartile (p75), and 95th percentile (p95)] 
Table 4 Food group intake and consumption rates in the optimized diets and changes of consumption rates from the observed diets

\begin{tabular}{|c|c|c|c|c|c|c|}
\hline Food group & $\begin{array}{l}\text { Intake in } \\
\text { optimized } \\
\text { diets (g) }\end{array}$ & $\begin{array}{l}\text { Consumption } \\
\text { rate in optimized } \\
\text { diets \% }\end{array}$ & $\begin{array}{l}\text { Consumption } \\
\text { rate in observed } \\
\text { diets \% }\end{array}$ & $\begin{array}{l}\text { Lactating mother } \\
\text { with increased } \\
\text { intake of this } \\
\text { food group \% }\end{array}$ & $\begin{array}{l}\text { Lactating mother with } \\
\text { decreased intake of } \\
\text { this food group \% }\end{array}$ & $\begin{array}{l}\text { Lactating mother with } \\
\text { food group added in } \\
\text { optimized diets } \%\end{array}$ \\
\hline Organ meat & 20 & 100 & 9 & 92 & 7 & 91 \\
\hline Leafy vegetable & 320 & 99 & 53 & 97 & 2 & 46 \\
\hline Condiment & 3 & 99 & 92 & 11 & 88 & 8 \\
\hline Egg & 46 & 99 & 56 & 50 & 42 & 43 \\
\hline Pork & 58 & 98 & 63 & 61 & 35 & 34 \\
\hline Red \& yellow vegetable & 180 & 97 & 28 & 95 & 2 & 69 \\
\hline Nut & 28 & 97 & 14 & 90 & 7 & 82 \\
\hline Milk powder & 28 & 96 & 1 & 94 & 1 & 94 \\
\hline Aquatic product & 44 & 95 & 30 & 73 & 22 & 65 \\
\hline Coarse grain & 97 & 90 & 10 & 88 & 3 & 80 \\
\hline Rice & 137 & 88 & 83 & 26 & 58 & 5 \\
\hline Banana & 64 & 84 & 12 & 75 & 9 & 72 \\
\hline Other vegetable & 96 & 77 & 69 & 62 & 15 & 8 \\
\hline Wheat flour product (non-fried) & 50 & 76 & 23 & 67 & 9 & 53 \\
\hline Various beans & 34 & 75 & 10 & 73 & 2 & 66 \\
\hline Potato & 35 & 64 & 15 & 57 & 6 & 50 \\
\hline Plant oil & 4 & 63 & 88 & 6 & 84 & 2 \\
\hline Processed fruit & 9 & 55 & 5 & 52 & 3 & 49 \\
\hline Wheat bun & 22 & 54 & 23 & 39 & 15 & 31 \\
\hline Poultry & 22 & 50 & 35 & 22 & 27 & 15 \\
\hline Non-fried snack & 4 & 50 & 16 & 40 & 11 & 36 \\
\hline Bread & 5 & 47 & 12 & 39 & 10 & 37 \\
\hline Wheat noodle & 27 & 45 & 22 & 30 & 15 & 23 \\
\hline Fast food & 11 & 43 & 17 & 32 & 9 & 27 \\
\hline Wheat flour product (fried) & 1 & 42 & 4 & 39 & 3 & 39 \\
\hline Soup & 75 & 40 & 35 & 12 & 26 & 5 \\
\hline Cake and ice-cream & 3 & 37 & 5 & 35 & 3 & 33 \\
\hline Processed meat & 8 & 37 & 7 & 32 & 4 & 30 \\
\hline Citrus fruit & 38 & 36 & 15 & 32 & 3 & 21 \\
\hline Other livestock meat & 5 & 33 & 8 & 27 & 7 & 26 \\
\hline Millet & 28 & 31 & 22 & 18 & 13 & 9 \\
\hline Apple and pear & 43 & 29 & 20 & 21 & 8 & 9 \\
\hline Fried snack & 1 & 29 & 1 & 28 & 1 & 27 \\
\hline Soybean & 8 & 27 & 25 & 8 & 19 & 2 \\
\hline Animal oil & 0 & 26 & 3 & 24 & 3 & 24 \\
\hline Liquid milk & 44 & 23 & 16 & 14 & 9 & 7 \\
\hline Tuber & 8 & 22 & 13 & 14 & 7 & 9 \\
\hline Other fruits & 20 & 19 & 13 & 14 & 5 & 7 \\
\hline Pickle & 1 & 10 & 6 & 7 & 3 & 4 \\
\hline Sugar sweetened beverage & 12 & 10 & 6 & 5 & 4 & 4 \\
\hline Yogurt & 3 & 8 & 2 & 6 & 1 & 6 \\
\hline
\end{tabular}


optimized diets by $91 \%$ of participants. Three food groups with consumption rate reached $99 \%$ in the optimized diets, including leafy vegetable, condiment, and egg. Increased intakes of leafy vegetable in optimized diets were found in $97 \%$ of subjects, while condiment were reported to have $88 \%$ of subjects with decreased intakes. Pork (98\%), red and yellow vegetable (97\%), nut (97\%), milk powder (96\%), aquatic product (95\%), coarse grain (90\%) were the six food groups with consumption rate as $90 \%$ or above. Compared with observed diets, only six food groups had higher percentage of decreased intakes in optimized diets, including condiment, rice, plant oil, poultry, soup, and soybean. For food groups that were added in the optimized diets but absent in the observed diets, there were nine food groups with more than $50 \%$ subject reported an addition: milk powder $(94 \%)$, organ meat $(91 \%)$, nut $(82 \%)$, coarse grain $(80 \%)$, banana $(72 \%)$, red and yellow vegetable $(69 \%)$, various beans (66\%), and wheat flour product (non-fried) (53\%).

Figure 1 presents the changes of food group intake quantities in the optimized diets from the observed diets. Among the 41 food groups, to achieve optimal diets that meet all nutrient recommendation in DRIs, increased intakes were needed for 16 food groups, and reduced quantities were found for 24 groups. Leafy vegetable showed the highest amount of increase in the optimized diet, followed by red and yellow vegetable, coarse grain, banana, various beans, milk powder, wheat flour product (non-fried), potato, nut, organ meat, as the top ten food groups with increased intakes compared to observed diets. For food groups with decrease in the optimized diets, the averaged amount of rice found the highest reduction as $64 \mathrm{~g}$. Other food groups with average reduced intakes higher than $15 \mathrm{~g}$ in optimal diets include soup, poultry, plant oil, soybean, egg, and millet. The food group of fried snack was the only group without change between observed and optimized diets.

A comparison of energy and nutrient contents between the observed and optimized diets was shown in Table 5. The energy intakes in the optimized diets of the 576 lactating women all reached $2300 \mathrm{kcal} / \mathrm{d}$ as the energy intake constraint set in the linear program model. The contributions to energy by both carbohydrate

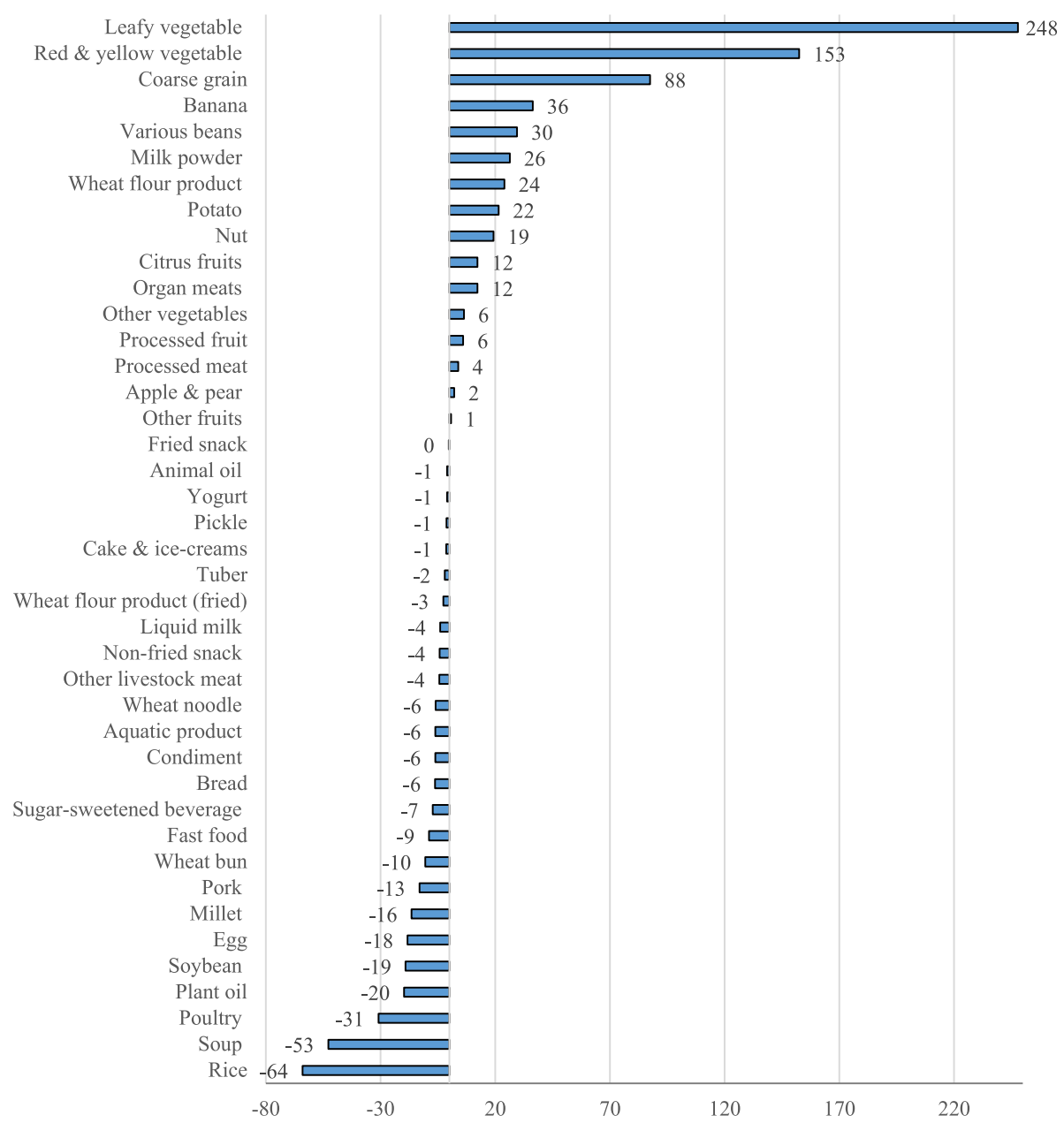

Fig. 1 Change of food group intake between the observed and the optimized diets 
Table 5 Comparison of nutrient contents between the observed and optimized diets

\begin{tabular}{|c|c|c|c|}
\hline \multirow[t]{2}{*}{ DRIs } & & \multicolumn{2}{|l|}{ Mean } \\
\hline & & Observed diets & Optimized diets \\
\hline Energy (kcal/d) & 2300 & 1836 & 2300 \\
\hline \multicolumn{4}{|l|}{ Macronutrients(AMDR) } \\
\hline Carbohydrate(\%) & $50-60$ & 49.56 & 58.74 \\
\hline Fat (\%) & $20-30$ & 36.35 & 27.45 \\
\hline \multicolumn{4}{|l|}{ Nutrients with $\mathrm{RNI}$ or $\mathrm{Al}^{\mathrm{a}}$} \\
\hline Protein (g/d) & 80 & 74.11 & 104.33 \\
\hline $\operatorname{Vitamin}_{1}(\mathrm{mg} / \mathrm{d})$ & 1.50 & 0.96 & 1.51 \\
\hline $\operatorname{Vitamin}_{2}(\mathrm{mg} / \mathrm{d})$ & 1.50 & 1.07 & 2.17 \\
\hline Vitamin C(mg/d) & 150 & 86.20 & 251.67 \\
\hline Vitamin $E(\mu \mathrm{g} / \mathrm{d})$ & 17 & 23.73 & 26.82 \\
\hline Vitamin A ( $\mu g R A E / d)$ & 1300 & 520.02 & 1300.14 \\
\hline $\operatorname{Vitamin}_{6}(\mathrm{mg} / \mathrm{d})$ & 1.7 & 0.87 & 1.74 \\
\hline $\operatorname{Niacin}(\mathrm{mg} / \mathrm{d})$ & 15 & 17.13 & 27.63 \\
\hline $\mathrm{Ca}(\mathrm{mg} / \mathrm{d})$ & 1000 & 466.72 & 1004.47 \\
\hline$P(m d / d)$ & 720 & 1014.12 & 1652.28 \\
\hline $\mathrm{K}(\mathrm{mg} / \mathrm{d})$ & 2400 & 1749.71 & 3808.69 \\
\hline$M g(m g / d)$ & 330 & 272.85 & 595.44 \\
\hline $\mathrm{Fe}(\mathrm{mg} / \mathrm{d})$ & 24 & 21.07 & 32.47 \\
\hline $\mathrm{Zn}(\mathrm{mg} / \mathrm{d})$ & 12 & 10.88 & 15.81 \\
\hline $\operatorname{Se}(\mu \mathrm{g} / \mathrm{d})$ & 78 & 57.31 & 78.47 \\
\hline $\mathrm{Cu}(\mathrm{mg} / \mathrm{d})$ & 1.4 & 1.85 & 3.09 \\
\hline$M n(m g / d)$ & 4.8 & 4.83 & 8.11 \\
\hline $\mathrm{Na}(\mathrm{mg} / \mathrm{d})$ & 1500 & 4114.29 & 1970.26 \\
\hline Fiber (g/d) & 25 & 9.74 & 25.39 \\
\hline
\end{tabular}

${ }^{a}$ Nutrients based on RNI include protein, calcium, phosphorus, magnesium, iron, selenium, zinc, vitamin $A$, vitamin $B_{1}$, vitamin $B_{2}$, vitamin $B_{6}$, niacin, vitamin C. Nutrients based on Al include potassium, sodium, manganese, vitamin $\mathrm{E}$ and dietary fiber

$(58.74 \%)$ and fat $(27.45 \%)$ in the optimal diets met the recommended ranges in AMDR. While in the observed diets, the contribution to energy from both fat and carbohydrate were outside the recommended value in AMDR. In the optimal diets of all the 576 participants, all nutrients reached RNI or AI values. It should be noted that nutrient contents of six nutrients including vitamin $\mathrm{A}$, vitamin $\mathrm{B} 1$, vitamin $\mathrm{B} 2$, vitamin $\mathrm{B} 6$, calcium, selenium, and dietary fiber just reached $100 \%$ of the DRIs value, suggesting these six nutrients as limiting nutrients in the optimized diets.

\section{Sources of nutrients and dietary patterns of optimized diets}

To understand how linear programming model modifies diets and generates optimized diets, the present study analyzed sources of nutrients and dietary clusters in the optimized diets.

Table 6 shows the sources of energy and nutrients in the optimized diets. Considering the recommendation to have at least 12 different kinds of foods on a daily basis from Chinese Dietary Guideline 2016 [30], we presented the contribution of energy and nutrients from top 12 food groups as well as top five food groups.

It can be seen from Table 6 that the Top 12 food group accounted for $69.63 \%$ of energy in the optimized diets. For nutrients, the contribution of nutrients from the corresponding top 12 food groups ranged from 72.93 to $97.87 \%$. For top five food groups, the ranges of contribution to energy and nutrients were between 40.16 and $88.95 \%$. Among individual food group, condiment showed the highest percentage with its contribution to sodium as $50.68 \%$. Food groups with contribution to certain nutrients higher than $20 \%$ also include: organ meat for vitamin A (30.34\%), liquid milk for calcium (28.73\%), leafy vegetable to vitamin C (28.64\%), red and yellow vegetable for vitamin A (27.35\%), pork to fat (23.61\%), and coarse grain to fiber (22.35\%).

From Table 6, we can also calculate the frequency of different food groups appearing in the top five contributors for energy and nutrients in the optimized diets, as below: coarse grain (16 times), leafy vegetable (13 times), liquid milk (11 times), nut (11 times), other vegetable (9 times), pork ( 7 times), aquatic product (7 times), egg (6 times), red and yellow vegetable (5 times), banana (5 times), organ meat (4 times), various beans ( 4 times), rice ( 3 times). There are 22 food group without presence in the top five contributors of energy or any nutrient in the optimized diets, indicating that these foods may have limited role to nutrient supply in the optimal diets.

Four reasonably sized clusters ( $>10 \%$ of sample size) were identified from the optimized diets (Table 7). Cluster $1(n=66)$ was characterized by higher intake of wheat bun, millet, apple and pear, and liquid milk, with least intake of milk powder. Lactating women within cluster $2(n=160)$ was characterized by red and yellow vegetable and milk powder, as well as lowest intake of bread and soup. The cluster with highest number of lactation mothers was Cluster $3(n=209)$, which showed higher intakes of wheat noodle, leafy vegetable, poultry, and banana, as well as lowest intake of other vegetables. Cluster $4(n=141)$ was characterized by higher intake of rice, citrus fruit, while with lowest intakes of millet and banana.

The distribution of lactating mothers in different clusters as shown in Table 8 . The results showed that the optimized diets for lactating mothers from Beijing in the northern China tend to be in Cluster 1 and Cluster 2, while mothers from the south in both Guangzhou and Suzhou are more likely be in Cluster 3 and Cluster 4 . Table 8 also presents distribution of subjects from 
Table 6 Contribution to energy and nutrients by food groups in the optimized diets

\begin{tabular}{|c|c|c|c|c|c|c|c|}
\hline & Contribu & n \% & & & & & \\
\hline & Top 12 & Top 5 & No.1 & No. 2 & No. 3 & No. 4 & No. 5 \\
\hline Energy & 69.63 & 41.71 & Coarse grain & Pork & Rice & Nut & Liquid milk \\
\hline & & & 13.01 & 8.32 & 7.08 & 6.72 & 6.58 \\
\hline Protein & 74.14 & 43.84 & Aquatic product & Pork & Coarse grain & Liquid milk & Egg \\
\hline & & & 11.29 & 9.03 & 8.76 & 7.98 & 6.78 \\
\hline Dietary fiber & 92.53 & 62.08 & Coarse grain & Other vegetable & Leafy vegetable & Nut & Various beans \\
\hline & & & 22.35 & 12.21 & 10.24 & 9.07 & 8.21 \\
\hline Vitamin $B_{1}$ & 78.55 & 48.21 & Coarse grain & Pork & $\begin{array}{l}\text { Wheat flour } \\
\text { product (non-fried) }\end{array}$ & $\begin{array}{l}\text { Red \& yellow } \\
\text { vegetable }\end{array}$ & Nut \\
\hline & & & 17.53 & 12.00 & 6.95 & 6.11 & 5.60 \\
\hline Vitamin $B_{2}$ & 78.41 & 51.37 & Liquid milk & Leafy vegetable & Organ meat & Milk powder & Egg \\
\hline & & & 17.84 & 9.71 & 8.75 & 8.35 & 6.73 \\
\hline Niacin & 77.41 & 46.75 & Nut & Coarse grain & Pork & Aquatic product & Other vegetable \\
\hline & & & 13.78 & 11.36 & 7.92 & 7.49 & 6.21 \\
\hline Vitamin C & 90.89 & 74.99 & Leafy vegetable & $\begin{array}{l}\text { Red \& yellow } \\
\text { vegetable }\end{array}$ & Other vegetable & Other fruit & Citrus fruit \\
\hline & & & 28.64 & 17.95 & 15.09 & 8.09 & 5.58 \\
\hline Vitamin E & 81.80 & 53.48 & Nut & Various beans & Coarse grain & Apple \& pear & Other vegetable \\
\hline & & & 19.77 & 9.38 & 9.14 & 7.90 & 7.29 \\
\hline $\mathrm{Ca}$ & 88.28 & 68.44 & Liquid milk & Leafy vegetable & Other vegetables & Milk powder & Aquatic product \\
\hline & & & 28.73 & 18.46 & 8.04 & 7.49 & 5.72 \\
\hline$P$ & 77.66 & 46.41 & Coarse grain & Liquid milk & Aquatic product & Nut & Leafy vegetable \\
\hline & & & 14.22 & 12.47 & 8.22 & 6.20 & 5.30 \\
\hline K & 79.34 & 47.67 & $\begin{array}{l}\text { Red \& yellow } \\
\text { vegetable }\end{array}$ & Leafy & Liquid milk & Coarse grain & Banana \\
\hline & & & 12.35 & 11.22 & 8.80 & 8.23 & 7.07 \\
\hline $\mathrm{Mg}$ & 79.58 & 49.64 & Coarse grain & Nut & Leafy vegetable & Banana & Other vegetable \\
\hline & & & 15.86 & 10.44 & 9.90 & 7.60 & 5.85 \\
\hline $\mathrm{Fe}$ & 73.27 & 46.16 & Leafy vegetable & Other vegetable & Coarse grain & Various beans & Organ meat \\
\hline & & & 11.83 & 10.96 & 9.94 & 7.24 & 6.19 \\
\hline $\mathrm{Zn}$ & 73.39 & 40.42 & Coarse grain & Pork & Liquid milk & Leafy vegetable & Aquatic product \\
\hline & & & 11.91 & 7.59 & 7.36 & 6.95 & 6.62 \\
\hline Se & 79.87 & 55.03 & Aquatic product & Organ meat & Egg & Pork & Liquid milk \\
\hline & & & 17.78 & 13.14 & 10.06 & 7.27 & 6.77 \\
\hline $\mathrm{Cu}$ & 72.93 & 40.16 & Nut & Coarse grain & Various beans & Other vegetable & Leafy vegetable \\
\hline & & & 10.69 & 8.94 & 8.83 & 5.93 & 5.77 \\
\hline $\mathrm{Mn}$ & 82.25 & 50.80 & Coarse grain & Nut & Rice & Banana & Other vegetable \\
\hline & & & 13.59 & 12.17 & 8.52 & 8.43 & 8.09 \\
\hline Vitamin A(RAE) & 97.87 & 88.95 & Organ meat & $\begin{array}{l}\text { Red \& yellow } \\
\text { vegetable }\end{array}$ & Leafy vegetable & Egg & Liquid milk \\
\hline & & & 30.34 & 27.35 & 16.70 & 9.57 & 5.00 \\
\hline Vitamin $B_{6}$ & 83.71 & 52.50 & $\begin{array}{l}\text { Red \& yellow } \\
\text { vegetable }\end{array}$ & Banana & Leafy vegetable & Nut & Coarse grain \\
\hline & & & 16.35 & 12.11 & 10.87 & 7.25 & 5.92 \\
\hline Fat & 85.92 & 66.55 & Pork & Nut & Liquid milk & Egg & Coarse grain \\
\hline & & & 23.61 & 18.44 & 12.72 & 6.80 & 5.19 \\
\hline
\end{tabular}


Table 6 Contribution to energy and nutrients by food groups in the optimized diets (Continued)

\begin{tabular}{|c|c|c|c|c|c|c|c|}
\hline & \multicolumn{7}{|c|}{ Contribution \% } \\
\hline & Top 12 & Top 5 & No.1 & No. 2 & No. 3 & No. 4 & No. 5 \\
\hline \multirow[t]{2}{*}{$\mathrm{Na}$} & 91.66 & 72.37 & Condiment & Leafy vegetable & Liquid milk & Egg & Aquatic product \\
\hline & & & 50.68 & 6.44 & 5.31 & 5.05 & 4.88 \\
\hline \multirow[t]{2}{*}{ Carbohydrate } & 78.64 & 51.16 & Coarse grain & Rice & $\begin{array}{l}\text { Wheat flour product } \\
\text { (non-fried) }\end{array}$ & Banana & Wheat bun \\
\hline & & & 18.71 & 10.80 & 8.11 & 6.85 & 6.69 \\
\hline
\end{tabular}

different lactating stages in different clusters. For lactating mothers at 0-4 day postpartum, $48.11 \%$ of the optimized diets were in Cluster 3, and 36.79\% were in Cluster 2. Cluster $3(48.66 \%)$ also accounts for the highest percentage in lactation stage 5-30 day postpartum, followed by Cluster 2 (22.99\%). But in 31-240 day postpartum, 36.04\% of the optimized diets for lactating women were classified as Cluster 4, higher than the other three clusters. In addition, subjects classified as Cluster 1 increased from $6.60 \%$ in $0-4$ day postpartum to $12.30 \%$ and $12.72 \%$ in $5-$ 30 days and 31-240 days.

\section{Discussion}

Adequate maternal nutrition in lactating stage is critical to ensure optimal growth of infants through breastmilk as well as maintaining nutrient storage in lactating mothers, therefore nutrient needs of lactating women are higher than non-lactating women [30]. However, the specific nutrition needs during lactation may remain as a challenge because of various reasons like cultural practice of confinement diets [1], lack of awareness and poor knowledge [32], in addition to inertia to dietary guidance identified in general population due to an array of cultural, socio-economic, behavioral factors [33]. Diet modeling approach such as linear programming offers the possibility to translate nutrient recommendation into realistic and personalized food advices [17]. Optimized diets generated by linear programming models in the present study could provide recommended micronutrients and macronutrients for sampled individual lactating mothers in the correct amounts and proportion, which meets the definition of an adequate diet by FIGO [1]. To our best knowledge, this study is the first one to employ linear programming to translate nutrient-based recommendation for Chinese lactating women into personalized diets that satisfy nutrient recommendation.

Our results show that substantial dietary modification from current diets of Chinese urban lactating women is needed to fulfill the nutritional recommendation for lactation stage. The average value of food group changes between the observed and the optimized diets in the current study was $1325 \mathrm{~g}$. In a study on designing optimal food intake patterns to achieve nutritional goals for Japanese adults by linear programing, the average amount of dietary changes from the observed to the optimized diets were $1262 \mathrm{~g} / \mathrm{d}$ for female aged 30-49y, and $1028 \mathrm{~g} / \mathrm{d}$ for male aged 30-49y [15]. In another study based on a representative sample of French population, individual diet modeling was applied to translate nutrient recommendations into weekly food plan [17]. The median increase in total diet weight was $1332 \mathrm{~g} /$ week, with the 5th percentile as $302 \mathrm{~g} /$ week and the 95th percentile as $1893 \mathrm{~g}$ week. The same group also reported that for the vast majority of French adults, it was mathematically impossible to design an optimized diet meeting all nutrient recommendation without expanding the diversity of foods consumed on a weekly basis [34]. Similar changes were identified to develop an optimal diet for the individuals of Chinese urban lactating women in our study.

The approach of reaching an optimal diets by linear programming model is to replace energy-dense food groups by nutrient-dense food groups. The 16 food groups with increased intakes in the optimized diets were nutrient-dense, while the 24 food groups with decreased amounts tend to be energy-dense. As the most nutrient-dense food [23], leafy vegetable and red-yellow vegetable showed highest increases in quantity. The increased amount of coarse grains in the optimized diets could be justified by the fact that coarse grains served as the top 5 contributors for energy and 15 nutrients. The replacement of refined grains like rice, millet, and wheat flour product by coarse grain with higher nutrient density in the current study is consistent with the results by Okubo et al. [15]. The consumption rates of food groups in the optimized diets showed that some specific food groups are key to achieving nutrient adequacy. There are 10 food groups with consumption rates reaching $90 \%$ or above. With the exception of condiment, the other nine food groups showed increased of intakes or addition of food groups compared to the observed diets. These nine food groups covered the major food categories recommended in the Chinese Dietary Pagoda [30], and may serve as core food groups in healthy dietary patterns for lactating women.

Food groups that could supply limiting nutrients may be prioritized by linear programming to ensure a solution for 
Table 7 Mean of food group intakes in the optimized diets by dietary clusters ${ }^{a}$

\begin{tabular}{|c|c|c|c|c|}
\hline \multirow[t]{2}{*}{ Food groups } & \multirow{2}{*}{$\begin{array}{l}\text { Cluster } 1^{\mathrm{b}} \\
N=66(11.46 \%)\end{array}$} & \multirow{2}{*}{$\begin{array}{l}\text { Cluster } 2 \\
N=160(27.78 \%)\end{array}$} & \multirow{2}{*}{$\begin{array}{l}\text { Cluster } 3 \\
N=209(36.28 \%)\end{array}$} & \multirow{2}{*}{$\begin{array}{l}\text { Cluster } 4 \\
N=141(24.48 \%)\end{array}$} \\
\hline & & & & \\
\hline Wheat bun & $44.96^{\mathrm{a}}$ & $28.50^{\mathrm{b}}$ & $15.16^{c}$ & $13.02^{c}$ \\
\hline Wheat noodle & $16.69^{b}$ & $19.31^{\mathrm{b}}$ & $38.79^{a}$ & $21.62^{b}$ \\
\hline Bread & $8.88^{\mathrm{a}}$ & $0.82^{c}$ & $6.04^{\mathrm{ab}}$ & $4.61^{\mathrm{b}}$ \\
\hline Rice & $103.21^{b c}$ & $90.75^{c}$ & $131.39^{b}$ & $211.89^{a}$ \\
\hline Wheat flour product (fried) & 2.01 & 1.85 & 0.94 & 1.44 \\
\hline Wheat flour product (non-fried) & $37.36^{\mathrm{bc}}$ & $63.25^{\mathrm{a}}$ & $55.82^{\mathrm{ab}}$ & $34.23^{c}$ \\
\hline Potato & 33.08 & 37.80 & 35.02 & 33.90 \\
\hline Tuber & $9.39^{a b}$ & $6.16^{\mathrm{b}}$ & $4.29^{b}$ & $16.64^{\mathrm{a}}$ \\
\hline Coarse grain & 96.88 & 92.89 & 98.45 & 97.94 \\
\hline Various beans & 29.47 & 39.24 & 32.69 & 30.28 \\
\hline Soybean & $10.19^{a}$ & $7.16^{\mathrm{ab}}$ & $5.80^{b}$ & $10.08^{\mathrm{a}}$ \\
\hline Nut & $22.17^{b}$ & $28.55^{\mathrm{a}}$ & $28.58^{\mathrm{a}}$ & $27.39^{\mathrm{a}}$ \\
\hline Millet & $55.32^{\mathrm{a}}$ & $29.40^{\mathrm{b}}$ & $31.62^{b}$ & $7.40^{c}$ \\
\hline Leafy vegetable & $177.88^{c}$ & $165.62^{c}$ & $465.03^{a}$ & $347.83^{b}$ \\
\hline Red \& yellow vegetable & $266.85^{b}$ & $315.03^{a}$ & $79.05^{d}$ & $134.90^{c}$ \\
\hline Other vegetables & $154.65^{\mathrm{a}}$ & $127.02^{\mathrm{ab}}$ & $42.62^{c}$ & $112.82^{b}$ \\
\hline Pickle & 0.45 & 1.57 & 0.77 & 1.05 \\
\hline Apple \& pear & $82.82^{\mathrm{a}}$ & $38.85^{\mathrm{b}}$ & $31.07^{\mathrm{b}}$ & $47.42^{b}$ \\
\hline Banana & $62.09^{b}$ & $61.66^{\mathrm{b}}$ & $82.85^{\mathrm{a}}$ & $39.3^{c}$ \\
\hline Citrus fruit & $37.64^{b}$ & $17.07^{\mathrm{bc}}$ & $8.88^{c}$ & $104.14^{\mathrm{a}}$ \\
\hline Other fruits & $32.94^{\mathrm{a}}$ & $31.39^{\mathrm{a}}$ & $7.03^{b}$ & $20.73^{\mathrm{ab}}$ \\
\hline Processed fruit & $10.57^{\mathrm{ab}}$ & $12.35^{\mathrm{a}}$ & $6.69^{b}$ & $6.08^{b}$ \\
\hline Pork & $52.97^{\mathrm{b}}$ & $54.30^{\mathrm{b}}$ & $57.05^{b}$ & $64.67^{\mathrm{a}}$ \\
\hline Poultry & $15.49^{b}$ & $14.74^{\mathrm{b}}$ & $28.54^{a}$ & $22.94^{\mathrm{ab}}$ \\
\hline Aquatic product & $39.25^{b}$ & $48.96^{\mathrm{a}}$ & $35.56^{\mathrm{b}}$ & $52.58^{\mathrm{a}}$ \\
\hline Other livestock meat & $8.98^{\mathrm{a}}$ & $2.44^{b}$ & $6.41^{\mathrm{a}}$ & $3.24^{\mathrm{b}}$ \\
\hline Organ meat & 19.95 & 19.66 & 19.92 & 19.56 \\
\hline Processed meat & 8.19 & 5.90 & 9.69 & 7.10 \\
\hline Egg & $46.87^{\mathrm{ab}}$ & $47.40^{\mathrm{a}}$ & $47.11^{\mathrm{a}}$ & $43.07^{b}$ \\
\hline Liquid milk & $276.57^{\mathrm{a}}$ & $9.22^{b}$ & $13.16^{\mathrm{b}}$ & $18.64^{\mathrm{b}}$ \\
\hline Yogurt & 0.00 & 5.21 & 0.50 & 4.42 \\
\hline Milk powder & $9.92^{c}$ & $48.38^{a}$ & $22.15^{b}$ & $23.87^{b}$ \\
\hline Cake \& ice-cream & 6.11 & 2.56 & 3.45 & 1.14 \\
\hline Non-fried snack & 1.65 & 2.93 & 5.32 & 3.78 \\
\hline Fast food & 14.99 & 8.40 & 13.17 & 10.58 \\
\hline Fried snack & 0.63 & 0.86 & 0.57 & 0.41 \\
\hline Soup & $85.05^{\mathrm{a}}$ & $45.22^{\mathrm{b}}$ & $85.77^{\mathrm{a}}$ & $87.95^{\mathrm{a}}$ \\
\hline Sugar-sweetened beverage & 19.35 & 8.36 & 8.24 & 17.10 \\
\hline Plant oil & 3.07 & 2.80 & 4.62 & 3.61 \\
\hline Animal oil & 0.17 & 0.19 & 0.38 & 0.19 \\
\hline Condiment & 2.84 & 2.83 & 2.63 & 2.75 \\
\hline
\end{tabular}

${ }^{a}$ Mean values between cluster without common letter differ, $P<0.05$ tested with ANOVA and bonferroni post hoc. The cluster with significantly higher intake for corresponding food group are marked bold. ${ }^{\mathrm{b}}$ Characteristic food groups for different clusters: Cluster 1-wheat bun, millet, apple and pear, and liquid milk; cluster 2-red and yellow vegetables and milk powder; cluster 3-wheat noodle, leafy vegetables, poultry, banana; cluster 4-rice, citrus fruits 
Table 8 Percentage of lactation mothers classified to dietary clusters

\begin{tabular}{|c|c|c|c|c|c|}
\hline & & Cluster $1^{\mathrm{a}}$ & Cluster 2 & Cluster 3 & Cluster 4 \\
\hline \multicolumn{6}{|l|}{ Difference cities } \\
\hline Beijing & $N$ & 46 & 89 & 53 & 26 \\
\hline$N=214$ & $\%$ & 21.50 & 41.59 & 24.77 & 12.15 \\
\hline Guangzhou & $N$ & 10 & 36 & 85 & 49 \\
\hline$N=180$ & $\%$ & 5.56 & 20.00 & 47.22 & 27.22 \\
\hline Suzhou & $N$ & 10 & 35 & 71 & 66 \\
\hline$N=182$ & $\%$ & 5.49 & 19.23 & 39.01 & 36.26 \\
\hline \multicolumn{6}{|c|}{$\begin{array}{l}\text { Different lactation } \\
\text { stages }\end{array}$} \\
\hline $0-4 d$ & $N$ & 7 & 39 & 51 & 9 \\
\hline$N=106$ & $\%$ & 6.60 & 36.79 & 48.11 & 8.49 \\
\hline $5-30 d$ & $N$ & 23 & 43 & 91 & 30 \\
\hline$N=187$ & $\%$ & 12.30 & 22.99 & 48.66 & 16.04 \\
\hline $31-240 d$ & $N$ & 36 & 78 & 67 & 102 \\
\hline$N=283$ & $\%$ & 12.72 & 27.56 & 23.67 & 36.04 \\
\hline
\end{tabular}

${ }^{a}$ Characteristic food groups for different clusters: Cluster 1-wheat bun, millet, apple and pear, and liquid milk; cluster 2-red and yellow vegetables and milk powder; cluster 3-wheat noodle, leafy vegetables, poultry, banana; cluster 4-rice, citrus fruits

meeting all constraints. For example, the consumption rate of banana reached $84 \%$, with $72 \%$ as new addition in the optimized diets. The reason to have increased amount of banana intake may be due to its contribution to vitamin B6 (12.11\%), which was identified as a limiting nutrient. Banana is also the top 5 contributor for magnesium, potassium, manganese, and energy. The increase of food groups that satisfy limiting nutrients in the optimization process could also be seen from organ meat. The consumption rate of organ meats is $100 \%$ in the optimized diets, as the only food group that is recommended for every lactating mothers. Indeed, the intake of organ meat reached the upper limit of food group intake constraint set as $20 \mathrm{~g}$. Organ meat is the major supplier of three limiting nutrients including vitamin A (30.34\%), selenium (13.14\%), and vitamin B2 (8.75\%), as well as top 5 food group sources for iron.

The K-means cluster analysis identified four clusters in the optimized diets, confirming that nutrient recommendations can be achieved in different ways, depending on the initial individual food patterns [17]. The optimized diets of lactating women showed distinctive differences between Beijing in the northern China and cities of Suzhou and Guangzhou from the south part of China. A national representative dietary survey also reported the geographical difference of dietary patterns between southern and northern China [35].

The objective function to minimize departure from observed diets ensured the optimized diets to reflect the differences in food choices at different lactation stages.
Cluster 3 is featured with higher intakes of wheat noodle, leafy vegetable, poultry, and banana. Cluster 3 also accounts for almost half of the subjects in the first month postpartum, followed by a decline to $24 \%$ after the first month. While the number of lactating women with an optimized diets classified as Cluster 4 increased from $8 \%$ in $0-4$ day postpartum to $16 \%$ in 5-30 day postpartum and 36\% in 31-240 day postpartum. Therefore, Cluster 3 maybe serve as the confinement diets, which also agreed with cultural practices in the southern part of China to have wheat noodle and poultry especially chicken at the first month after giving birth [11]. A longitudinal study on Chinese dietary pattern from 1991 to 2009 with a sample of 9253 Chinese adults identified two stable dietary patterns including a traditional southern dietary pattern, which was characterized by high intakes of rice, fresh leafy vegetables, low-fat red meat, pork, organ meats, poultry and fish/seafood and low intakes of wheat flour and maize/coarse grains [36]. The traditional southern dietary pattern is similar to Cluster 4 in the optimized diets in terms of both characteristic food groups as well as features of subjects. Therefore, by setting an objective function as minimized deviation from current diets, the optimized diets could be nutritionally adequate but still reflects the food choices by geographical region and duration of lactation.

The major strength of this study was to apply linear programming for the first time in a Chinese lactation population to develop individualized, optimal diets that meet nutrient recommendations with least departure from the current diet. The result showed that suggests that the nutrient needs of lactating mothers in China may only be met after substantial dietary changes and with the addition of nutrient-dense food. As shown among European adults in the Food4Me European randomized controlled trial, personalized nutrition advices enabled by linear programming approaches produced larger and more appropriate changes in dietary behavior than non-personalized, conventional healthy eating guidelines [24]. So this study provides knowledge foundation to implement digital nutrition approach for large scale intervention to provide individualized recommendation to support healthier eating behavior of lactating women in China.

Several limitations of this study warrant mention. First, the observed diets used in the current study was based on one-day $24 \mathrm{~h}$ recall, which limited the ability to generate optimized diet plans for longer period due to the absence of information about day-to-day variation. In addition, due to limitation of Chinese Food Composition Table, the current study did not estimate some nutrients relevant to maternal and infant nutrition such as fatty acids, folic acids, vitamin D. Moreover, the optimized diets were built on the hypothesis that the observed diets may reflect 
individual preference. But in reality, many factor could contribute to the choices of food, so information about actual personal preference will clearly help improve the approach. Lastly, this study does not include intervention component. An intervention study may be needed to show improvement in dietary quality through personalized nutrition recommendation enabled by linear programming approach, compared to conventional, non-personalized dietary guideline.

\section{Conclusions}

In conclusion, linear programming could help translate nutrient recommendations into personal diet advices for a sample of urban lactating mothers from China. Substantial changes including increasing diversity and intakes of nutrient-dense foods were needed to achieve optimal diets. Such information can provide references for establishing dietary guidelines and meal plans for lactation mothers, and also support for maintaining a healthy diet with adequate nutrient supply for both breastfeeding and mothers' own nutrition storage.

\section{Abbreviations}

Al: Adequate Intake; AMDR: Acceptable Macronutrient Distribution Ranges; DRIs: Dietary Reference Intakes; EER: Estimated Energy Requirement; FIGO: International Federation of Gynecology and Obstetrics; MING Study: Maternal Infant Nutrition and Growth Study; PI-NCD: Proposed Intakes for Preventing Non-Communicable Chronic Diseases; RNI: Recommended Nutrient Intake; UL: Tolerable Upper Intake Level

\section{Acknowledgments}

We acknowledged the help of Dr. Sheri Volger for improving language of the manuscript. The authors thank every participants joining the survey. We also sincerely appreciate the invaluable assistance from the local maternal and child medical centers. Thanks also to the sponsorship for MING study from Nestlé Nutrition Institute China and Nestlé Research Center.

\section{Funding}

The MING study was supported by Nestlé Nutrition Institute China and Nestlé Research Center.

\section{Availability of data and materials}

The datasets used and/or analysed during the current study are available from the corresponding author on reasonable request.

\section{Author contributions}

KY conducted data analysis and drafted the manuscript. WL, YZ and PW designed the MING study and executed the survey. WZ, YX and AZ were responsible of collecting dietary intake data. All authors read and approved the final manuscript.

\section{Ethics approval and consent to participate}

This study was conducted according to the guidelines in the Declaration of Helsinki. All procedures involving human participants were approved by the Medical Ethics Research Board of Peking University (NO.IRB00001052-11042). Written informed consents were obtained from all participants. The registration number of the MING study in ClinicalTrials.gov is NCT01971671.

\section{Consent for publication}

Not applicable.

\section{Competing interest}

Co-author WL is employed by Nestlé Nutrition Institute and co-author KY is employed by Nestlé Research Center. There are no patents, products in development or marketed products to declare.

\section{Publisher's Note}

Springer Nature remains neutral with regard to jurisdictional claims in published maps and institutional affiliations.

\section{Author details}

${ }^{1}$ Department of Nutrition and Food Hygiene, School of Public Health, Peking University, Beijing, China. ${ }^{2}$ CAS Key Laboratory of Pathogenic Microbiology and Immunology, Institute of Microbiology, Chinese Academy of Science, Beijing, China. ${ }^{3}$ Department of Social Medicine and Health Education, School of Public Health, Peking University, Beijing, China. ${ }^{4}$ Nestlé Nutrition Institute, Beijing, China.

Received: 29 November 2017 Accepted: 6 September 2018 Published online: 18 September 2018

\section{References}

1. Hanson MA, Bardsley A, De-Regil LM, Moore SE, Oken E, Poston L, et al. The International Federation of Gynecology and Obstetrics (FIGO) recommendations on adolescent, preconception, and maternal nutrition: "Think Nutrition First". Int J Gynaecol Obstet. 2015;131 Suppl 4:S213S253. doi: https://doi.org/10.1016/S0020-7292(15)30023-0. PMID: 26433230. [CrossRef PubMed].

2. Picciano MF. Pregnancy and lactation: physiological adjustments, nutritional requirements and the role of dietary supplements. J Nutr 2003;133(6): 1997S-2002S. PMID: 12771353. [CrossRef PubMed].

3. Giammarioli S, Sanzini E, Ambruzzi AM, Chiarotti F, Fasano G. Nutrient intake of Italian women during lactation. Int J Vitam Nutr Res. 2002 72(5):329-335. doi: https://doi.org/10.1024/0300-9831.72.5.329. PMID: 12463109.[CrossRef PubMed].

4. Fowles ER, Walker LO. Correlates of dietary quality and weight retention in post-partum women. J Community Health Nurs. 2006;23(3):183-197. doi: https://doi.org/10.1207/s15327655jchn2303_5. PMID: 16863403. [CrossRef PubMed].

5. Moran LJ, Sui Z, Cramp CS, Dodd JM. A decrease in diet quality occurs during pregnancy in overweight and obese women which is maintained post-partum. Int J Obes (Lond). 2013;37(5):704-711. doi: https://doi.org/10. 1038/ijo.2012.129. PMID: 22868828. [CrossRef PubMed].

6. Cucó G, Fernández-Ballart J, Sala J, Viladrich C, Iranzo R, Vila J, Arija V. Dietary patterns and associated lifestyles in preconception, pregnancy and postpartum. Eur J Clin Nutr. 2006 60(3):364-371. doi: https://doi.org/10. 1038/sj.ejcn.1602324. PMID: 16340954. [CrossRef PubMed].

7. Crozier SR, Robinson SM, Godfrey KM, Cooper C, Inskip HM. Women's dietary patterns change little from before to during pregnancy. J Nutr. 2009,139(10):1956-1963. doi: https://doi.org/10.3945/jn.109.109579. PMID: 19710161. [CrossRef PubMed].

8. Sotres-Alvarez D, Herring AH, Siega-Riz AM. Latent transition models to study women's changing of dietary patterns from pregnancy to 1 year postpartum. Am J Epidemiol. 2013;177(8):852-861. doi: https://doi.org/10. 1093/aje/kws303. PMID: 23538942. [CrossRef PubMed].

9. Dos Santos Q, Sichieri R, Marchioni DM, Verly Junior E. Brazilian pregnant and lactating women do not change their food intake to meet nutritional goals. BMC Pregnancy Childbirth. 2014;14:186. doi: https://doi.org/10.1186/ 1471-2393-14-186. PMID: 24890188.[CrossRef PubMed].

10. Chen LW, Low YL, Fok D, Han WM, Chong YS, Gluckman P, et al. Dietary changes during pregnancy and the postpartum period in Singaporean Chinese, Malay and Indian women: the GUSTO birth cohort study. Public Health Nutr. 2014;17(9):1930-1938. doi: https://doi.org/10.1017/ S1368980013001730. PMID: 23806144. [CrossRef PubMed].

11. Raven JH, Chen Q, Tolhurst RJ, Garner P. Traditional beliefs and practices in the postpartum period in Fujian Province, China: a qualitative study. BMC Pregnancy Childbirth. 2007; 7: 8. doi: https://doi.org/10.1186/1471-2393-7-8. PMID: 17584930. [CrossRef PubMed].

12. Zhao A, Xue Y, Zhang Y, Li W, Yu K, Wang P. Nutrition concerns of insufficient and excessive intake of dietary minerals in lactating women: a cross-sectional survey in three cities of China. PLoS ONE. 2016; 11(1): e0146483. doi:https://doi.org/10.1371/journal.pone.0146483. PMID: 26730592. [CrossRef PubMed].

13. Chen H, Wang P, Han Y, Ma J, Troy FA, Wang B. Evaluation of dietary intake of lactating women in China and its potential impact on the health of mothers and infants. BMC Women's Health. 2012;12:18. doi:https://doi.org/ 10.1186/1472-6874-12-18. PMID: 22800437. [CrossRef PubMed]. 
14. Irz X, Leroy $P$, Réquillart $V$, Soler LG. Beyond wishful thinking: integrating consumer preferences in the assessment of dietary recommendations. PLoS One. 2016;11(6):e0158453. doi: https://doi.org/10.1371/journal.pone.0158453. PMID: 27362764. [CrossRef PubMed].

15. Okubo H, Sasaki S, Murakami K, Yokoyama T, Hirota N, Notsu A, et al. Designing optimal food intake patterns to achieve nutritional goals for Japanese adults through the use of linear programming optimization models. Nutr J. 2015; 14:57. doi: https://doi.org/10.1186/s12937-015-0047-7. PMID: 26048405. [CrossRef PubMed].

16. Briend A, Darmon N, Ferguson E, Erhardt JG. Linear programming a mathematical tool for analyzing and optimizing children's diets during the complementary feeding period. J Pediatr Gastroenterol Nutr 2003;36(1):1222. PMID: 12499991. [CrossRef PubMed].

17. Maillot M, Vieux F, Amiot MJ, Darmon N. Individual diet modeling translates nutrient recommendations into realistic and individual-specific food choices. Am J Clin Nutr. 2010, 91(2):421-430. doi: https://doi.org/10.3945/ajcn.2009. 28426. PMID: 19939986. [CrossRef PubMed].

18. Wilson N, Nghiem N, Ni Mhurchu C, Eyles H, Baker MG, Blakely T. Foods and dietary patterns that are healthy, low-cost, and environmentally sustainable: a case study of optimization modeling for New Zealand. PLoS One. 2013; 8(3):e59648. doi: https://doi.org/10.1371/journal.pone.0059648. PMID: 23544082. [CrossRef PubMed].

19. Donati M, Menozzi D, Zighetti C, Rosi A, Zinetti A, Scazzina F. Towards a sustainable diet combining economic, environmental and nutritional objectives. Appetite. 2016, 106: 48-57. doi: https://doi.org/10.1016/ j.appet. 2016. 02.151. PMID: 26921487. [CrossRef PubMed].

20. Horgan GW, Perrin A, Whybrow S, Macdiarmid JI. Achieving dietary recommendations and reducing greenhouse gas emissions: modelling diets to minimise the change from current intakes. Int J Behav Nutr Phys Act. 2016, 13:46. doi: https://doi.org/10.1186/s12966-016-0370-1. PMID: 27056829. [CrossRef PubMed].

21. Fahmida U, Santika O, Kolopaking R, Ferguson E. Complementary feeding recommendations based on locally available foods in Indonesia. Food Nutr Bull. 2014, 35(4 Suppl):S174-S179. doi: https://doi.org/10.1177/ 15648265140354S302. PMID: 25639135. [CrossRef PubMed].

22. Hlaing LM, Fahmida U, Htet MK, Utomo B, Firmansyah A, Ferguson EL. Local food-based complementary feeding recommendations developed by the linear programming approach to improve the intake of problem nutrients among 12-23-month-old Myanmar children. Br J Nutr. 2016, 116 Suppl 1: S16-S26. doi: https://doi.org/10.1017/S000711451500481X. PMID: 26696232. [CrossRef PubMed].

23. Maillot M, Drewnowski A. A conflict between nutritionally adequate diets and meeting the 2010 dietary guidelines for sodium. Am J Prev Med. 2012, 42(2): 174-179. doi: https://doi.org/10.1016/j.amepre.2011.10.009. PMID: 22261214. [CrossRef PubMed].

24. Celis-Morales C, Livingstone KM, Marsaux CF, Macready AL, Fallaize R, O'Donovan CB, et al. Effect of personalized nutrition on health-related behaviour change: evidence from the Food4me European randomized controlled trial. Int J Epidemiol. 2016. doi: https://doi.org/10.1093/ije/dyw186 PMID: 27524815. [CrossRef PubMed].

25. Yang Y. China food composition second edition. Beijing: Peking University Medical Press; 2009.

26. Marcoe K, Juan W, Yamini S, Carlson A, Britten P. Development of food group composites and nutrient profiles for the MyPyramid Food Guidance System. J Nutr Educ Behav. 2006;38:S93-107. doi: https://doi.org/10.1016/j. jneb.2006.05.014. PMID: 17116599. [CrossRef PubMed].

27. Masset G, Monsivais P, Maillot M, Darmon N, Drewnowski A. Diet optimization methods can help translate dietary guidelines into a cancer prevention food plan. J Nutr. 2009;139(8):1541-1548. doi: https://doi.org/10. 3945/jn.109.104398. PMID: 19535422. [CrossRef PubMed].

28. Anderson AM, Earle MD. Diet planning in the third world by linear and goal programming. J Oper Res Soc. 1983;34:9-16. doi: https://doi.org/10.2307/ 2581598. [CrossRef].

29. China Nutrition Society. China DRIs handbook (2013). Beijing: China Standard Press; 2014

30. China Nutrition Society. Dietary guideline for Chinese (2016). Beijing People's Medical Publishing House; 2016.

31. Thorpe MG, Milte CM, Crawford D, McNaughton SA. A comparison of the dietary patterns derived by principal component analysis and cluster analysis in older Australians. Int J Behav Nutr Phys Act. 2016;13:30. doi:https://doi.org/ 10.1186/s12966-016-0353-2. PMID: 26928406. [CrossRef PubMed].
32. Charlton K, Yeatman H, Lucas C, Axford S, Gemming L, Houweling F, et al. Poor knowledge and practices related to iodine nutrition during pregnancy and lactation in Australian women: pre- and post-iodine fortification. Nutrients. 2012, 4(9):1317-1327. doi: https://doi.org/10.3390/nu4091317. PMID: 23112919. [CrossRef PubMed].

33. Webb D, Byrd-Bredbenner C. Overcoming consumer inertia to dietary guidance. Adv Nutr 2015 6(4):391-396. doi: https://doi.org/10.3945/an.115. 008441 PMID: 26178023. [CrossRef PubMed].

34. Maillot M, Vieux F, Ferguson EF, Volatier JL, Amiot MJ, Darmon N. To meet nutrient recommendations, most French adults need to expand their habitual food repertoire. J Nutr. 2009,139(9):1721-1727. doi: https://doi.org/ 10.3945/jn.109.107318. PMID: 19625703. [CrossRef PubMed].

35. He Y, Ma G, Zhai F, Li Y, Hu Y, Feskens EJ, Yang X. Dietary patterns and glucose tolerance abnormalities in Chinese adults. Diabetes Care. 2009, 32(11):1972-1976. doi: https://doi.org/10.2337/dc09-0714. PMID: 19675202. [CrossRef PubMed].

36. Batis C, Sotres-Alvarez D, Gordon-Larsen P, Mendez MA, Adair L, Popkin B. Longitudinal analysis of dietary patterns in Chinese adults from 1991 to 2009. Br J Nutr. 2014,111(8):1441-1451. doi: https://doi.org/10.1017/ S0007114513003917. PMID: 24331247. [CrossRef PubMed].

\section{Ready to submit your research? Choose BMC and benefit from:}

- fast, convenient online submission

- thorough peer review by experienced researchers in your field

- rapid publication on acceptance

- support for research data, including large and complex data types

- gold Open Access which fosters wider collaboration and increased citations

- maximum visibility for your research: over $100 \mathrm{M}$ website views per year

At BMC, research is always in progress.

Learn more biomedcentral.com/submissions 